
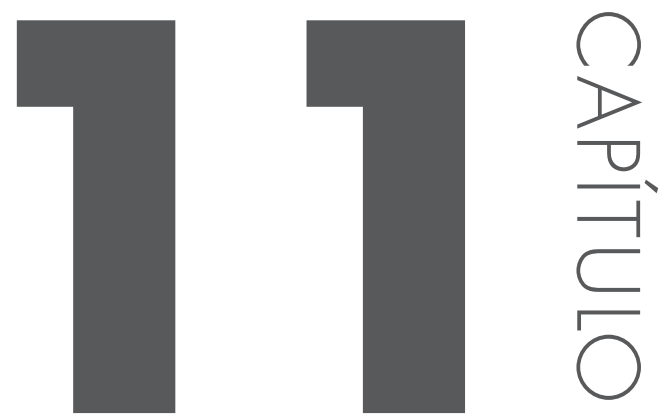

\title{
Desaguamento de lama de ROCHA FOSFÁtICA: PASTA MINERAL
}

\section{Vaz, J. 1;}

Silva, A.C. 2*;

Silva, E.M.S. 2;

Araujo, V.R. 1

1 Graduando em Engenharia de Minas, Universidade Federal de Goiás;

2 Prof. Departamento de Engenharia de Minas, Universidade Federal de Goiás;

* email: ancarsil@ufg.br 
Resumo: $\bigcirc$ desaguamento é uma das operações unitárias industriais mais importantes e é amplamente adotada em diferentes indústrias. Atualmente, a disposição dos rejeitos do processamento mineral é um grande problema, devido ao impacto ambiental gerado. $O$ processamento da rocha fosfática na Anglo American Fosfato Brasil, situada em Catalão/ GO gera aproximadamente $180 \mathrm{t} / \mathrm{h}$ de rejeitos de $480 \mathrm{t} / \mathrm{h}$ alimentadas na usina (aproximadamente 37,5\% da alimentação da usina), com 5 a $10 \%$ de sólidos e aproximadamente $14 \%$ de P2O5. Atualmente os rejeitos são encaminhados diretamente para a barragem de rejeitos. O presente trabalho propõe a geração de pasta produzida a partir do rejeito gerado na usina. O líquido clarificado, obtido através de ensaios de sedimentação, foi drenado e a polpa remanescente foi encaminhada para o segundo estágio, consistindo de filtragem a vácuo. A adição de floculante permitiu uma taxa de sedimentação mais rápida e uma performance mais alta no estágio de desaguamento, sendo o último devido ao fato do material floculado ter sido retido pelo meio filtrante e não passar pelo mesmo, fato que ocorria sem a adição do mesmo. Os resultados obtidos foram satisfatórios para a produção de pasta usando rejeito com aproximadamente $65 \%$ de porcentagem de sólidos.

\title{
Palavras-chave: Lama de rocha fosfática; Pasta mineral; Desaguamento
}

\author{
Vaz, J.; Silva, A.C.; Silva, E.M.S.; Araujo, V.R.; "DESAGUAMENTO DE LAMA DE ROCHA FOSFÁTICA: PASTA MINERAL", p. \\ 170-186 . In: Seminário de Pesquisa, Pós-Graduação e Inovação da Regional Catalão (2. : 2014 : Goiás) Coletânea \\ Interdisciplinar em Pesquisa, Pós-Graduação e Inovação - Volume 3 : Engenharias, Saúde e Gestão. Anais [livro eletrônico] / \\ organizado por Adriana Freitas Neves, Idelvone Mendes Ferreira, Maria Helena de Paula, Petrus Henrique Ribeiro dos Anjos. \\ São Paulo: Blucher, 2015. ISBN: 978-85-8039-113-8, DOI 10.5151/9788580391138-V3_Cap11
}




\section{Introdução}

Os rejeitos gerados durante as etapas de concentração de minérios oferecem uma série de problemas ambientais relacionados à sua disposição, normalmente sob a forma de barragens, as quais demandam grandes áreas, contamina os recursos hídricos, possuem elevado custo de construção, além de ser exigido por lei um longo tempo de monitoramento desse passivo ambiental. Com isso, estudos relacionados com a disposição de rejeitos na forma de pasta mineral são corroborados em muitos países, já que esse método oferece maior recuperação e recirculação de agua, menores custos de investimento e operação e menor impacto ambiental.

Geralmente, os minérios requerem processamento a úmido, sendo, então, 
necessário que se recupere a maior parte da agua adicionada durante a operação industrial. A separação sólido-líquido se torna, portanto, uma importante etapa no âmbito do processamento mineral. Este processo tem sido bastante estudado devido não só ao aspecto de recuperação da água, recurso cada vez mais escasso e oneroso para a indústria, bem como ao grande consumo energético (Amarante, 2001).

Segundo França e Massarani (2004) a sedimentação é um dos processos de separação sólido-líquido baseada na diferença entre as densidades dos constituintes de uma suspensão; a remoção das partículas sólidas presentes em uma corrente líquida se dá pela ação do campo gravitacional, o que oferece ao processo as características de baixo custo e grande simplicidade operacional. A larga utilização industrial dos sedimentadores promove um crescente interesse no conhecimento do dimensionamento e operação desses equipamentos, com a finalidade de melhorar a sua utilização e eficiência no atendimento aos objetivos operacionais.

No caso de suspensões/polpas minerais contendo partículas menores do que $10 \mu \mathrm{m}$, o processo de separação sólido-líquido é extremamente afetado pelo efeito de dispersão das partículas, causado pelo movimento browniano característico dos coloides, o qual dificulta a sedimentação. Nestes casos, deve-se avaliar a necessidade de aglomeração prévia das partículas - coagulação/floculação - antes de submetêlas à operação de separação propriamente dita. A presença de partículas ultrafinas tem efeito nas eficiências de espessamento, reduz as taxas de filtragem e pode acumular mais umidade que a desejada nas tortas oriundas da filtração. Por isso, a importância do pré-tratamento dessas polpas.

Segundo Hogg (1999), a floculação é um processo de agregação de partículas finas dispersas em flocos. O processo envolve três etapas principais:

- Desestabilização da suspensão de partículas finas, isto é, eliminação de qualquer repulsão entre partículas devida às cargas elétricas etc., que se opõem à agregação;

- Formação e crescimento do floco, isto é, o desenvolvimento de agregados partícula-partícula por colisão e adesão;

- Degradação do floco, isto é, mecanismos de quebra devido ao cisalhamento, turbulência etc., no rejeito.

O espessamento é a operação de separação de uma suspensão de sólidos para obter uma polpa mais densa e uma fase líquida clarificada. O mecanismo clássico dessa operação é a sedimentação influenciada pela força da gravidade, em tanques cilíndricos que, normalmente, são construídos de diferentes materiais, tais como: madeira, aço ou cimento. Nos espessadores convencionais, a polpa é alimentada pela parte superior e no centro do tanque, permitindo sua saída através de duas 
aberturas, uma no centro do fundo e outra na periferia da parte superior do tanque através de uma calha que circunda o mesmo. Pela abertura do fundo, há descarga da polpa e pelo vertedouro se obtém o líquido clarificado. Um conjunto de pás acionado pelo eixo ligado ao centro do tanque leva o material sedimentado até a abertura de descarga. Os espessadores pequenos podem apresentar fundo plano, mas comumente este fundo tem uma pequena inclinação em direção ao centro, facilitando a descarga do produto (Barreda e Valadão, 2008).

Segundo Massarani (2001) o projeto de sedimentadores contínuos está relacionado ao cálculo da área da seção de sedimentação e da altura do equipamento, sendo que os dados necessários para o dimensionamento de um sedimentador contínuo, bem como outras informações operacionais desta unidade, são determinados por meio de ensaios práticos utilizando provetas de 2,0 L em laboratório.

Oliveira et alii (2004) definem a filtragem como o processo de separação sólidolíquido através de um meio poroso (meio filtrante) que retém os sólidos e permite a passagem do líquido. Na indústria mineral, é aplicada normalmente após o espessamento.

A escolha do meio filtrante é um dos aspectos mais importante para que se tenha uma filtragem eficiente. Sua função é atuar como um suporte para a torta formada. Uma das características mais importantes necessárias ao meio filtrante escolhido é sua capacidade de reter sólidos sem cegamento dos poros que permitem a passagem do líquido, além de ser mecanicamente forte e resistente à corrosão. Usualmente, realiza-se a desobstrução do meio filtrante através do sopro realizado na descarga da torta.

De acordo com Wills e Napier-Munn (2006), os meios filtrantes podem ser fabricados a partir de algodão, lã, linho, juta, nylon, seda, fibra de vidro, carbono poroso, metais, rayon e outros produtos sintéticos. No entanto, novos materiais têm surgido com o intuito de substituir os materiais usualmente utilizados. Dentre esses materiais destacam-se as mantas geotêxteis.

Lima (2003) apud Schujmann (2010) define os geotêxteis como sendo mantas permeáveis, flexíveis e finas produzidas a partir de fibras sintéticas ou naturais. Os geotêxteis apresentam algumas vantagens em relação aos meios filtrantes convencionalmente utilizados, tais como: menor espessura, características definidas e controladas, por se tratar de um produto produzido industrialmente, facilidade de instalação, manutenção e baixo custo.

Os geotêxteis podem ter os poros colmatados por partículas finas em suspensão (diâmetro médio de 7 a $50 \mu \mathrm{m}$ ) durante a filtragem mecânica. As partículas coloidais podem ser capturadas pelos poros por interações físicas, eletrostáticas ou químicas. Em condições desfavoráveis para interações químicas e eletrostáticas, o 
comportamento dos coloides pode ser diferente das partículas de granulometria maior em que não serão mecanicamente filtradas, seguindo assim o fluxo do líquido.

Segundo Osório et alii (2008), uma pasta mineral pode ser conceituada como um sistema coloidal que se apresenta como um fluido homogêneo, no qual não ocorre a segregação granulométrica das partículas e que, ao ser disposto suavemente em superfícies estáveis, não apresenta drenagem significativa de água.

Uma definição simples e prática de pasta mineral, de acordo com Theriault et alii (2001), é que são rejeitos que devem ser suficientemente desaguados, apresentam uma velocidade de fluxo crítica quando são bombeados, não sofrem segregação quando são depositados e produz um mínimo de água quando são descarregados a partir de tubulações.

\section{Metodologia}

as amostras de rejeito de rocha fosfática utilizadas foram provenientes da empresa Anglo American Fosfato Brasil, situada na cidade de Catalão/GO, Brasil, e correspondiam à lama gerada no circuito de cominuição da empresa, sendo hoje a mesma descartada na barragem de rejeitos.

Para determinação do melhor floculante a ser utilizado, foram realizados testes de sedimentação livre em provetas de 2,0 L. Inicialmente as amostras foram homogeneizadas e volumes de 2,0 $\mathrm{L}$ foram coletados para alimentação das provetas. Foram utilizados nove floculantes de três fabricantes diferentes, de forma a determinar qual apresentaria maior eficiência em relação à formação dos flocos, tempo de sedimentação e estabilidade dos flocos na filtragem a vácuo. Os floculantes utilizados são apresentados no quadro 1.

Quadro 1 - Floculantes testados e sua descrição. Fonte: Autoria própria.

\begin{tabular}{|c|c|c|}
\hline Fabricante & Nome comercial & Descrição \\
\hline \multirow{7}{*}{ Basf } & Magnafloc 10 & $\begin{array}{c}\text { Poliacrilamida ligeiramente aniônica, } \\
\text { de peso molecular muito elevado }\end{array}$ \\
\cline { 2 - 3 } & Magnafloc 155 & $\begin{array}{c}\text { Poliacrilamida aniônica de elevado } \\
\text { peso molecular }\end{array}$ \\
\cline { 2 - 3 } & Magnafloc 351 & $\begin{array}{c}\text { Poliacrilamida não-iônica de alto } \\
\text { peso molecular }\end{array}$ \\
\cline { 2 - 3 } & Magnafloc 1011 & $\begin{array}{c}\text { Poliacrilamida aniônica de peso } \\
\text { molecular muito elevado }\end{array}$ \\
\hline
\end{tabular}




\begin{tabular}{|c|c|c|}
\hline \multirow{3}{*}{ Clariant } & Bozefloc A61 BT & $\begin{array}{c}\text { Copolímero de acrilato de sódio e } \\
\text { acrilamida }\end{array}$ \\
\cline { 2 - 3 } & Bozefloc C630 & $\begin{array}{c}\text { Copolímero de acrilato de sódio e } \\
\text { acrilamida }\end{array}$ \\
\hline \multirow{7}{*}{ Kemira } & Superfloc A-100 & $\begin{array}{c}\text { Poliacrilamida aniônica de alto peso } \\
\text { molecular e com grau muito baixo de } \\
\text { carga aniônica }\end{array}$ \\
\cline { 2 - 3 } & Superfloc A-130 & $\begin{array}{c}\text { Poliacrilamida aniônica de alto peso } \\
\text { molecular e com grau médio de carga } \\
\text { aniônica }\end{array}$ \\
\cline { 2 - 3 } & Superfloc C-492 & $\begin{array}{c}\text { Poliacrilamida de alto peso molecular } \\
\text { e carga catiônica relativa muito baixa }\end{array}$ \\
\cline { 2 - 3 } & Superfloc C-494 & $\begin{array}{c}\text { Poliacrilamida de alto peso molecular } \\
\text { e carga catiônica relativa média }\end{array}$ \\
\hline
\end{tabular}

O controle de $\mathrm{pH}$ foi realizado em pHmetro modelo T-1000 da Gehaka, sendo todos os testes realizados em $\mathrm{pH}$ 7. Após a sedimentação o líquido clarificado gerado era drenado, sendo a sua turbidez medida com o auxílio de um turbidímetro portátil digital modelo HI 93703C da Hanna Instruments. O material floculado era filtrado a vácuo por seis minutos utilizando uma bomba de vácuo Prismatec 132 ligada a um frasco de Kitassato de $2000 \mathrm{~mL}$. Um suporte para o filtro de foi acoplado ao Kitassato, onde foram colocados o material ser filtrado e o meio filtrante (na forma de discos de $13 \mathrm{~cm}$ de diâmetro). A figura 1 apresenta o aparato experimental utilizado para a realização dos ensaios de filtragem a vácuo. Para a realização dos ensaios de filtragem a vácuo estabeleceu-se o uso do floculante Superfloc A-100 da Kemira na dosagem de $20 \mathrm{~mL} / \mathrm{L}$ devido bom resultado obtido nos testes de floculação bem como ao fato do mesmo gerar flocos passíveis de filtragem. Em testes com os outros floculantes os flocos gerados eram completamente destruídos na filtragem a vácuo, impedindo assim a retida do líquido. $O$ quadro 2 apresenta os meios filtrantes utilizados nos ensaios.

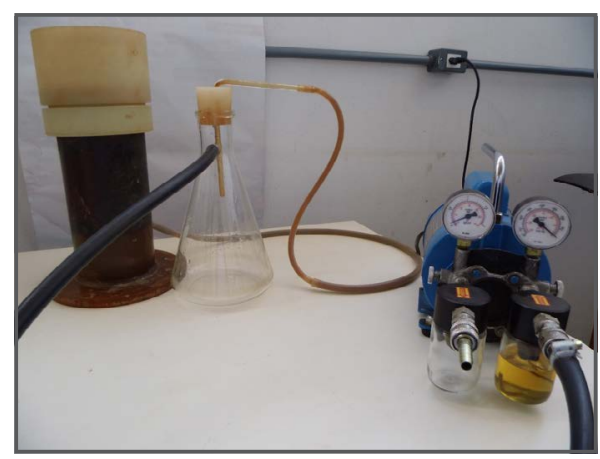

Figura 1 - Filtro a vácuo utilizado nos testes. Fonte: Autoria própria. 
Quadro 2 - Meios filtrantes usados nos testes. Fonte: Autoria própria.

\begin{tabular}{|c|c|c|c|}
\hline Fabricante & Meios filtrantes & Fibra & $\begin{array}{c}\text { Permeabilidade } \\
{\left[\mathbf{m}^{\left.\mathbf{3} / \mathbf{m i n} / \mathbf{m}^{2}\right]}\right.}\end{array}$ \\
\hline Remae & $1097-\mathrm{EL}$ & Nylon, múltiplos fios & $7,0-14,0$ \\
\hline Remae & $1097-\mathrm{TE}$ & Nylon, múltiplos fios & $1,5-6,0$ \\
\hline Remae & $1142-\mathrm{T}$ & Nylon, múltiplos fios & $10,0-16,0$ \\
\hline Remae & $4230-\mathrm{T}$ & Polipropileno, com fio simples & $60,0-80,0$ \\
\hline Remae & $4233-\mathrm{TC}$ & Polipropileno, com fio simples & $15,0-20,0$ \\
\hline Remae & $4400-\mathrm{T}$ & Polipropileno, com fio múltiplo & $0,6-1,2$ \\
\hline Remae & $4520-\mathrm{T}$ & Polipropileno, com fio múltiplo & $1,5-5,0$ \\
\hline Remae & $4710-\mathrm{T}$ & Polipropileno, com fio múltiplo & $0,3-0,5$ \\
\hline Bidim geo. & CC-10 & Geotêxtil não-tecido 100\% poliéster & $4,2-7,2$ \\
\hline
\end{tabular}

Após a filtragem a pasta gerada era encaminhada para secagem em estufa a uma temperatura de $120^{\circ} \mathrm{C}$ por cinco horas. Tanto a pasta seca gerada, quanto o meio filtrante usado foram pesados após a secagem, de modo a permitir o cálculo da porcentagem de sólido na pasta produzida.

\section{Resultados e discussões}

a análise química das amostras de rejeitos de rocha fosfática utilizada neste trabalho foi obtida por difração de raios-X, e é apresentada no quadro 3. A análise granulométrica é dada no quadro 4. Ambas as análises foram realizadas pela Anglo American Fosfato Brasil.

Quadro 3 - Composição do rejeito da rocha fosfática (em óxidos). Fonte: Autoria própria.

\begin{tabular}{|c|c|c|c|c|c|c|c|c|}
\hline \hline Óxido & $\mathrm{P}_{2} \mathrm{O}_{5}$ & $\mathrm{CaO}$ & $\mathrm{Al}_{2} \mathrm{O}_{3}$ & $\mathrm{Fe}_{2} \mathrm{O}_{3}$ & $\mathrm{SiO}_{2}$ & $\mathrm{BaO}$ & $\mathrm{MgO}$ & $\mathrm{Nb}_{2} \mathrm{O}_{5}$ \\
\hline$\%$ & 14,20 & $17,2 \sigma$ & 1.96 & 25,03 & 22,36 & 1,69 & 2,33 & 0,63 \\
\hline
\end{tabular}


Quadro 4 - Análise granulométrica dos rejeitos da rocha fosfática.

Fonte: Autoria própria.

\begin{tabular}{|l|c|c|c|c|c|}
\hline Malha [\#] & 200 & 270 & 325 & 400 & -400 \\
\hline \% passante acumulada & 15,97 & 21,78 & 25,36 & 26,38 & 100,00 \\
\hline
\end{tabular}

Os gráficos 1, 2 e 3 mostram os resultados médios para os ensaios de sedimentação. Cada teste foi realizado três vezes. Em todos os testes, o pH foi ajustado a sete, para evitar fases adicionais de tratamento de agua em uma possível utilização industrial.

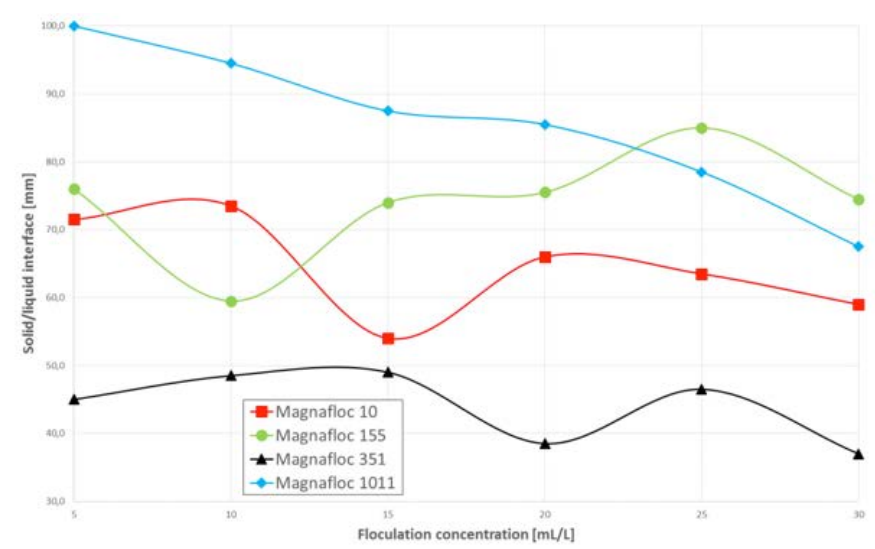

Gráfico 1 - Resultados dos testes com floculantes produzidos pela Basf. Fonte: Autoria Própria

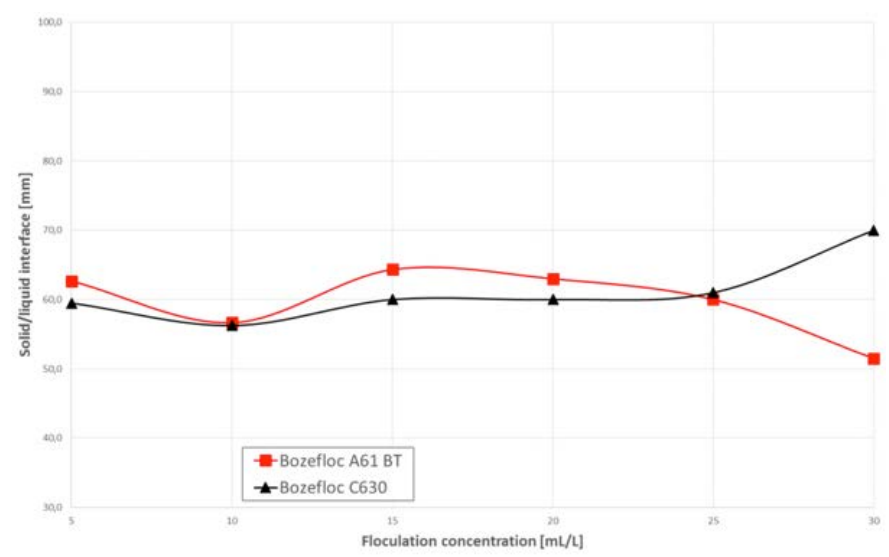

Gráfico 2 - Resultados dos testes com floculantes produzidos pela Clariant.

Fonte: Autoria própria. 


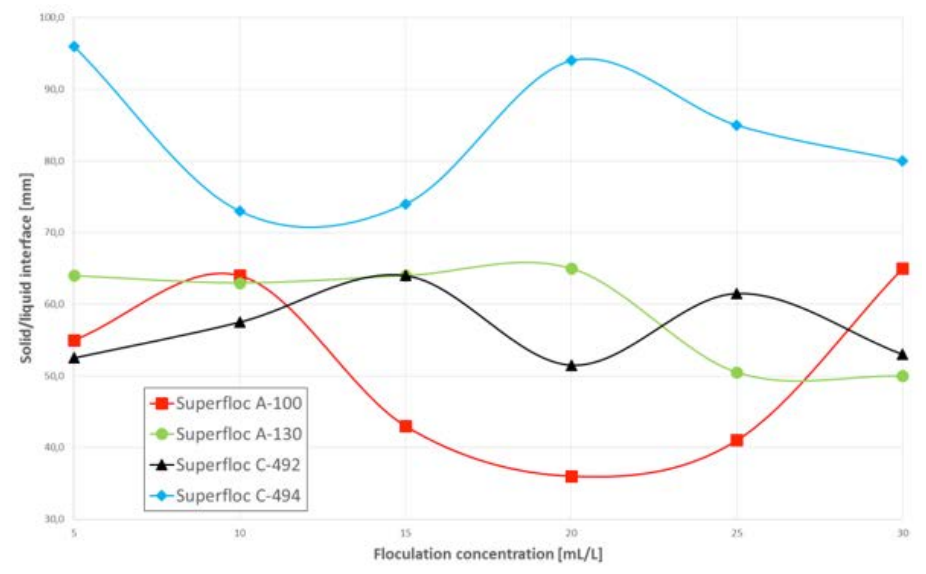

Gráfico 3 - Resultados dos testes com floculantes produzidos pela Kemira.

Fonte: Autoria Própria

O gráfico 4 mostra a relação entre o tempo de sedimentação das partículas em relação a interface solido/liquido, no teste de sedimentação livre utilizando o floculante, Kemira Superfloc A-100 na concentração de $20 \mathrm{~mL} / \mathrm{L}$ e a figura 6 traz o material já floculado com a utilização do mesmo. A figura 2 apresenta o rejeito de rocha fosfática floculado com o reagente Kemira Superfloc A-100 na concentração de $20 \mathrm{~mL} / \mathrm{L}$ ao final do teste de sedimentação em proveta de 2,0 L.

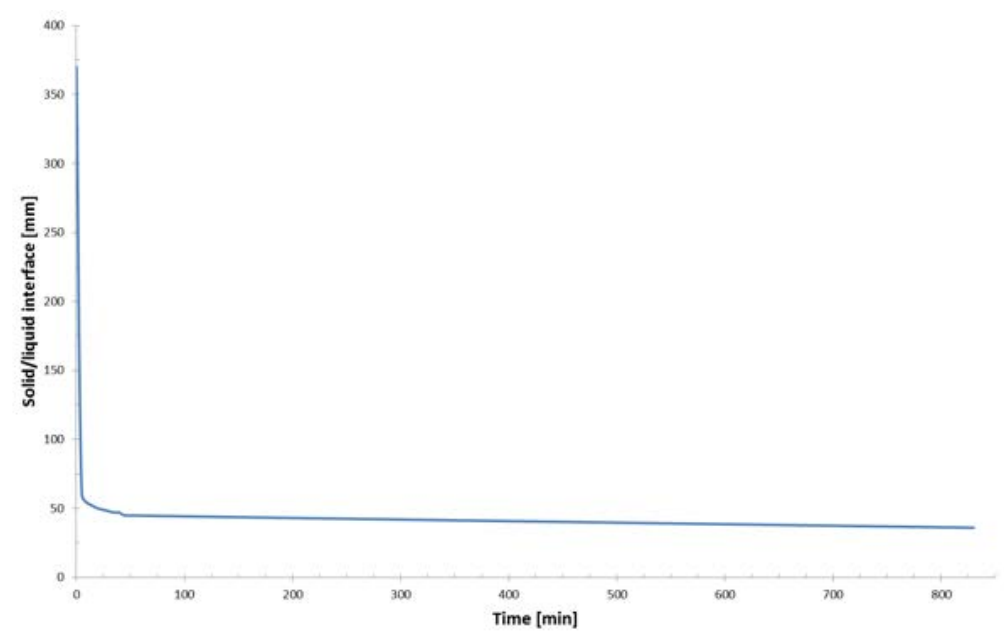

Gráfico 4 - Tempo de sedimentação versus a altura da interface sólido / líquido para o Kemira Superfloc A-100 na concentração de 20 mL / L. Fonte: Autoria própria. 


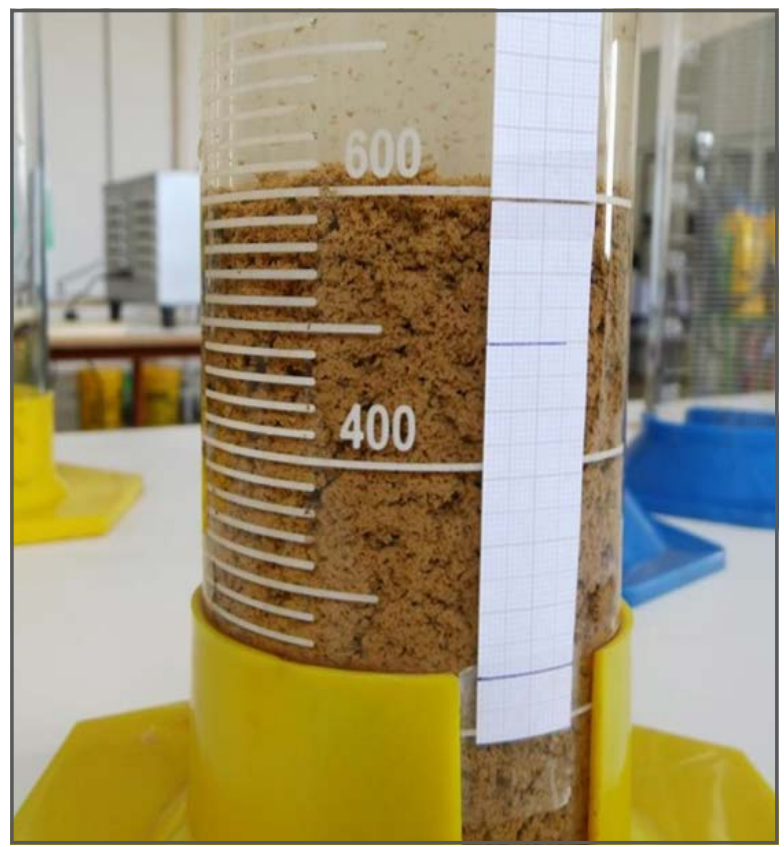

Figura 2 - Rejeito de rocha fosfática floculado com Kemira Superfloc A-100 na concentração de 20 mL / L. Fonte: Autoria própria.

A figura 3 apresenta seis diferentes estágios de um teste de sedimentação em proveta de 2,0 L. Pode-se notar que no início do testes (figura 8a) a polpa está homogeneamente distribuída em toda proveta e, com o passar do tempo, é possível notar a formação de uma interface entre a fase líquida e a fase líquido + sólido, ou zona difusa (figura $4 \mathrm{~b}$ a $4 \mathrm{e}$ ). A figura $4 \mathrm{f}$ apresenta o líquido produzido após ser drenado da proveta no final do teste.

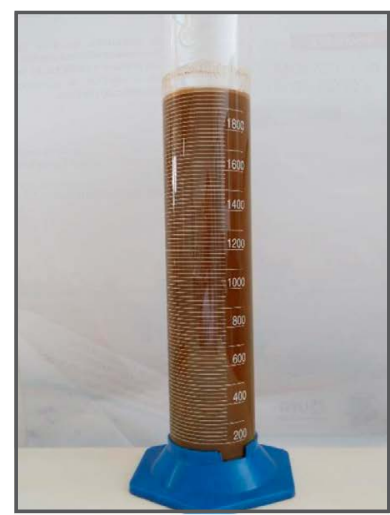

(a)

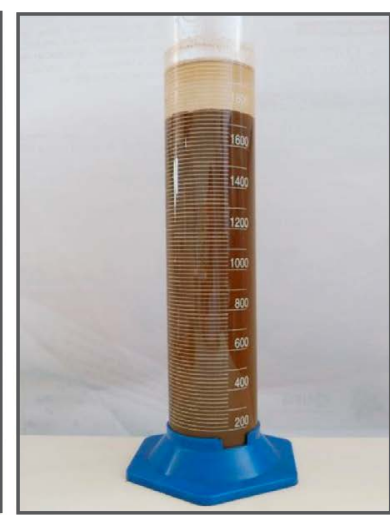

(b)

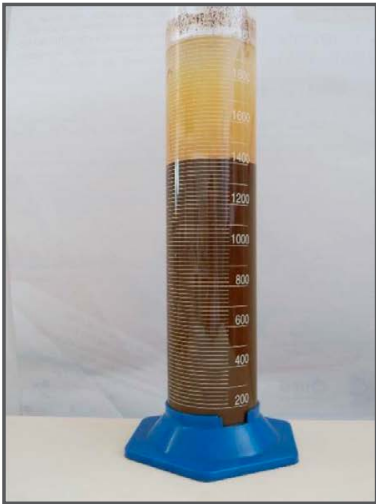

(c) 




(d)

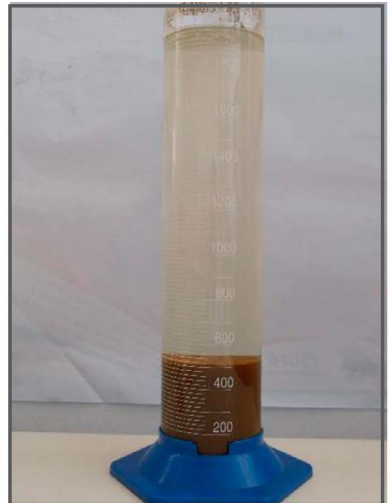

(e)

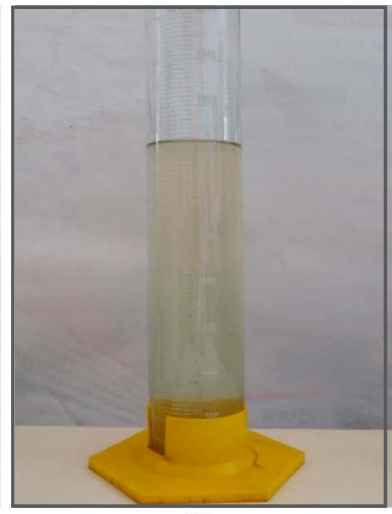

(f)

Figura 3 - Sequência mostrando seis diferentes momentos de um teste de sedimentação em proveta de 2,0 L. Fonte: Autoria própria.

A figura 4 apresenta seis pastas geradas nos testes. Pode-se perceber que ainda existe água presente na mesma, mas que a textura e reologia do material gerado é visualmente compatível com o esperado para as pastas minerais.

O quadro 5 mostra os resultados obtidos dos testes de filtragem a vácuo, mostrando o volume de liquido filtrado, e percentagem em massa de sólidos na pasta e a queda de pressão desde o início até ao final dos testes. Uma pressão de vácuo elevado indica uma alta permeabilidade de ambos os meios filtrantes e polpa, enquanto que uma pressão baixa de vácuo indica uma baixa permeabilidade. Podese notar que os melhores resultados (meio filtrante Remae 4230-T e 4233-TC) de acordo com a percentagem de sólidos na pasta, a queda de pressão era de zero, embora ambas as pressões iniciais e finais de vácuo foram baixas. Isto é explicado pela presença de dutos capilares na pasta, que permitem a passagem de um fluxo de agua, porém não de forma espontânea. Para os outros meios filtrantes foi notada a obstrução de poros dos mesmos após os testes, necessitando de uma limpeza para remoção de partículas restantes, o que explica a queda de pressão. Para esses ensaios, a altura da pasta era superior e a percentagem de sólidos mais baixa.
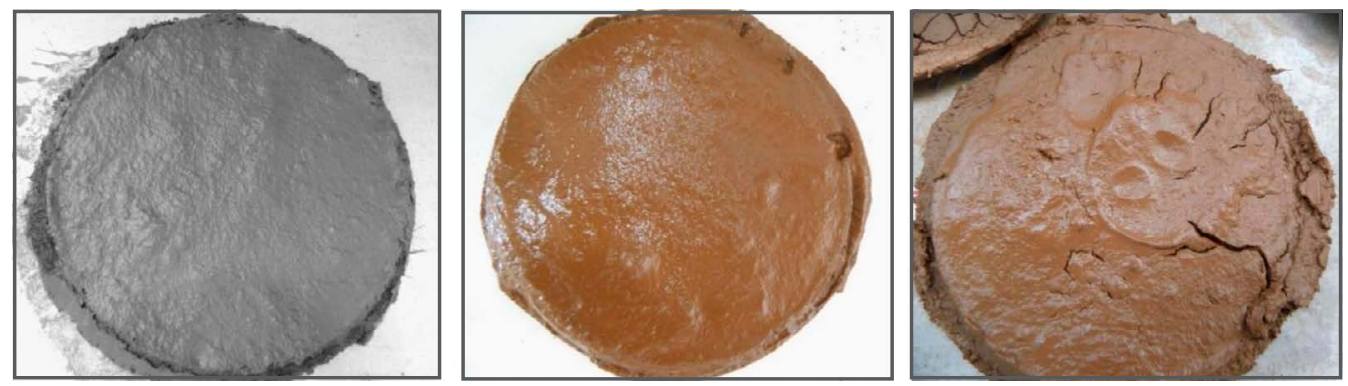

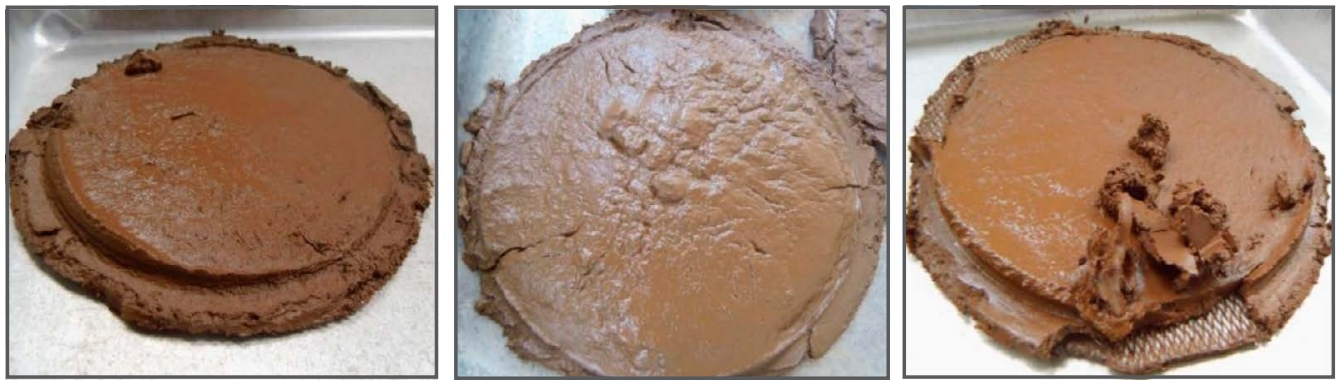

Figura 4 - Pastas minerais produzidas a partir do rejeito de rocha fosfática. Fonte: Autoria própria.

\begin{tabular}{|c|c|c|c|c|c|c|}
\hline \multirow{2}{*}{ Meios Filtrantes } & \multirow{2}{*}{$\begin{array}{c}\text { Floculante } \\
(\mathrm{mL})\end{array}$} & \multirow{2}{*}{$\begin{array}{c}\text { Filtrado } \\
(\mathrm{mL})\end{array}$} & \multirow{2}{*}{$\begin{array}{l}\text { Massa da } \\
\text { pasta }(g)\end{array}$} & \multirow{2}{*}{$\begin{array}{c}\text { Perc. de } \\
\text { sólidos }(\%)\end{array}$} & \multicolumn{2}{|c|}{ Pressão (mm Hg) } \\
\hline & & & & & Inicial & Final \\
\hline 1097-EL & 615,00 & 440,00 & 112,49 & 59,53 & $-500,00$ & $-350,00$ \\
\hline 1097-TE & 190,71 & 128,57 & 81,90 & 54,59 & $-400,00$ & $-302,86$ \\
\hline $1142-\mathrm{T}$ & 161,67 & 96,67 & 83,17 & 52,32 & $-390,00$ & $-316,67$ \\
\hline $4230-\mathrm{T}$ & 175,00 & 91,67 & 81,56 & 62,42 & $-100,00$ & $-100,00$ \\
\hline 4233-TC & 175,00 & 93,33 & 79,95 & 64,55 & $-103,33$ & $-103,33$ \\
\hline $4400-\mathrm{T}$ & 175,00 & 115,00 & 71,75 & 47,56 & $-433,33$ & $-323,33$ \\
\hline $4520-\mathrm{T}$ & 166,67 & 95,00 & 66,16 & 50,50 & $-256,67$ & $-173,33$ \\
\hline $4710-\mathrm{T}$ & 189,29 & 117,86 & 94,32 & 56,10 & $-140,00$ & $-120,00$ \\
\hline Bidim & 190,00 & 112,14 & 96,68 & 47,81 & $-211,43$ & $-147,14$ \\
\hline
\end{tabular}

Quadro 5 - Resultados da filtragem a vácuo. Fonte: Autoria Própria

O gráfico 5 mostra a percentagem de sólidos obtidos nos diferentes meios filtrantes, com o uso do Kemira Superfloc A-100 (20 mL /L). Onde o melhor resultado foi encontrado com o Remae $4233-\mathrm{TC}$ (64,55\% de sólidos). O tecido geotêxtil não apresentou um resultado bom $(47,81 \%)$ e, muitas vezes mostrou rejeitos remanescentes nele depois do teste, sendo sua limpeza muito difícil, devido ao seu tecido. O gráfico 6 mostra a queda de pressão para os diferentes meios filtrantes testados, no qual o Remae 4233-TC e Remae 4230-T, que apresentaram os melhores resultados, como dito anteriormente, não tiveram nenhuma queda de pressão. 


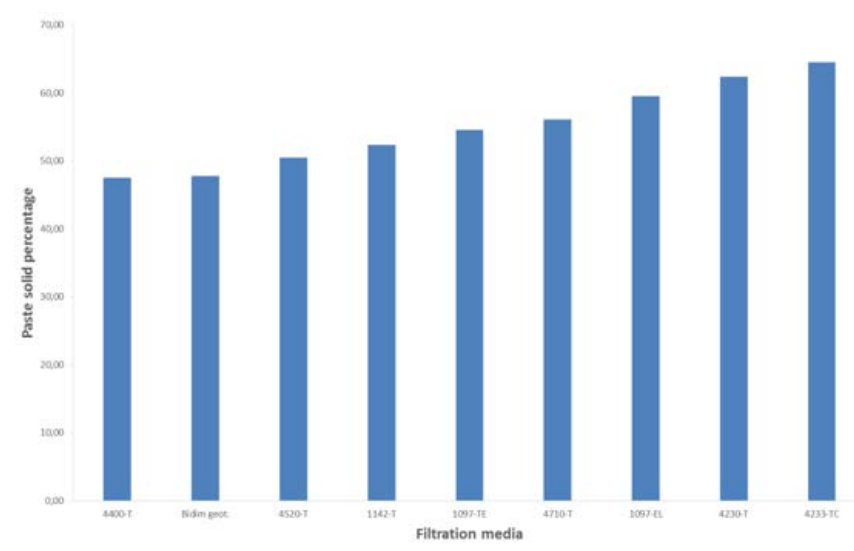

Gráfico 5 - Porcentagem de sólidos média na pasta mineral produzida.

Fonte: Autoria própria.

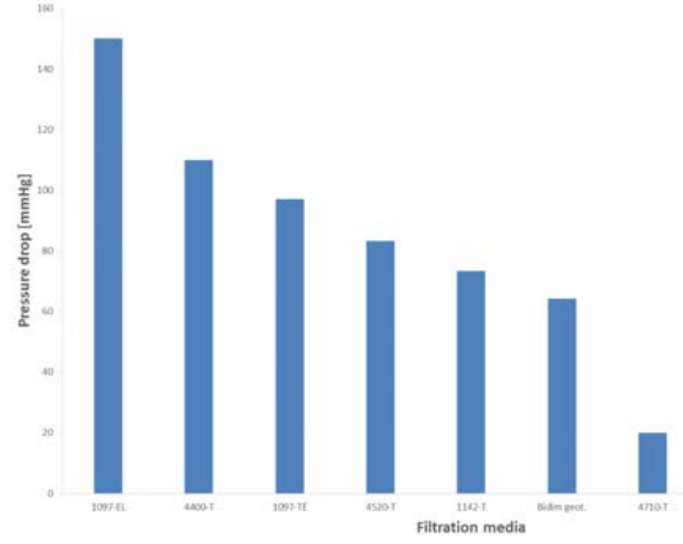

Gráfico 6 - Queda de pressão média nos ensaios de filtragem a vácuo. Fonte: Autoria própria.

\section{Conclusões}

os resultados encontrados foram satisfatórios, pois através da metodologia aplicada, com a utilização de floculante (Kemira Superfloc A-100), para auxiliar na sedimentação livre e posterior filtragem a vácuo, com os meios filtrantes Remae 4233-TC e Remae 4230-T, conseguiu-se obter uma pasta com percentagem de solido retidos maior que $60 \%$. 
A utilização desta estratégia pode ser uma boa solução para o problema de disposição de rejeitos, substituindo o atual sistema de barragens de rejeitos pela deposição de rejeitos em pasta, além de levar a uma economia considerável pois necessitaria de um espaço físico menor para seu armazenamento, traria também uma diminuição no impacto ambiental causado por essas gigantescas barragens.

\section{Agradecimentos}

osautoresagradecemaoapoiofinanceiro,imprescindível paraodesenvolvimento do presente trabalho, das agências brasileiras de fomento à pesquisa CNPq, CAPES, FAPEG e FUNAPE, à Universidade Federal de Goiás, pelo apoio dado ao mesmo e à empresa Anglo American Fosfato Brasil, Unidade Catalão-GO pela doação de material e liberação da divulgação dos dados da pesquisa. 


\section{Phosphate rock slury dewatering: mineral paste}

Abstract: The dewatering stage is among the most important industrial unit operations, and is widely adopted in many different industries. Nowadays, mineral processing tailings disposal is a big problem due to the environmental degradation it causes. The phosphate rock processing in Anglo American Phosphate Brazil, situated in Catalão/Go/Brazil, generates around 180 $\mathrm{t} / \mathrm{h}$ of tailings for a plant feed of $480 \mathrm{t} / \mathrm{h}$ (approximately $37.5 \%$ of the processing plant feed), with 5 to $10 \%$ of solids and approximately $14 \%$ of P2O5. Nowadays, the tailings are sent direct to the tailings dam. The present work proposes paste production using the tailings from the phosphate rock processing plant. Through decantation of a tailings sample, a clarified liquid was obtained and drained. The decanted pulp then went through a second stage consisting of vacuum filtration. Flocculant addition in this stage generated a faster sedimentation rate and a higher dewatering performance in next stage of dewatering, because the flocculated material was retained by the filter medium instead of passing through it. The results were satisfactory for paste tailings production with a solid percentage of around $65 \%$.

Keywords: Phosphate rock slurry; Mineral paste; Dewatering.

\section{Referências bibliográficas}

AMARANTE, S.C. Filtragem na Indústria Mineral, in Metalurgia \& Materiais, VOL. 57, $\mathrm{n}^{\circ} .515$, ABM, São Paulo/SP, pp. 647-648, 2001.

BARREDA, R.H., VALADÃO, G.E.S. Desenvolvimento de equipamento produtor de pasta mineral, dissertação de mestrado apresentada ao curso de Pós-Graduação em Engenharia Metalúrgica e de Minas, Belo Horizonte/ MG, 150 pp, 2008.

FRANÇA, S.C.A., MASSARANI, G. Separação sólido-líquido, in LUZ, A. B., SAMPAIO, J. A., ALMEIDA, S. L. M. (Ed.). Tratamento de Minérios. Rio de Janeiro: CETEM/MCT, pp. 573-609, 2004.

HOGG, R. Flocculation and dewatering, in Int. J. Miner. Process. 58, pp. 223-236, 2000. 
MASSARANI, G. Fluidodinâmica em sistemas particulados. 2a. ed. Rio de Janeiro: Ed. UFR, pp. $152,2001$.

OLIVEIRA, M.L.M., LUZ, J.A.M., LACERDA, C.M.M. Espessamento e Filtragem. Ouro Preto: Escola de Minas da Universidade Federal de Ouro Preto - UFOP, Ouro Preto/MG, pp. 122, 2004.

OSÓRIO, C.A., ARAUJO, A.C., VALADÃO, G.E. Estudo de Características de Algumas Pastas Minerais. Tecnologia em Metalurgia e Materiais, São Paulo, v. 4, n. 3, pp. 50-55, 2008.

THERIAULT, J. A., FROSTIAK, J., WELCH, D. Surface Disposal of Paste Tailigns at the Bulyanhulu Gold Mine, Tanzania, pp. 1-8, 2001.

WILLS, B. A., NAPIER-MUNN, T. Mineral Processing Technology. Elsevier Science \& Technology Books, pp. 450, 2006. 